\title{
Tendências pedagógicas do ensino de psicopatologia nos cursos de graduação em psicologia
}

\author{
Pedagogical trends of teaching of psychopathology in \\ graduation courses of psychology
}

\author{
Conrado Neves Sathler', Catia Paranhos Martins', Elenita Sureke Abílio 2,3 \\ ' Discurso e Identidade - TDI, Grupo de Pesquisa Território, Laboratório Clínica de Psicologia Aplicada, \\ Faculdade de Ciências Humanas, Universidade Federal da Grande Dourados, Dourados (MS), Brasil. \\ ${ }^{2}$ Discurso e Identidade - TDI, Grupo de Pesquisa Território, Curso de Psicologia, Laboratório Clínica de \\ Psicologia Aplicada, Faculdade Anhanguera de Dourados, Dourados (MS), Brasil. \\ ${ }^{3}$ Centro de Atendimento Psicossocial - Álcool e Drogas, Secretaria Municipal de Saúde de Dourados, Dourados \\ (MS), Brasil.
}

Recebido: Jul. 19, 2017

Aceito: Dez. 27, 2017

\section{COMO CITAR ESTE ARTIGO}

Sathler CN, Martins CP, Abílio ES.

Tendências pedagógicas do ensino

de psicopatologia nos cursos

de graduação em psicologia.

Interdisciplinary Journal of Health

Education. 2017 Jan-Jul;2(1):61-67. http://

dx.doi.org/10.4322/ijhe.2016.026

\section{CORRESPONDÊNCIA}

Conrado Neves Sathler

Faculdade de Ciências Humanas,

Universidade Federal da Grande Dourados

Rodovia Dourados, Itahum - Km 12,

Unidade 2, Cidade Universitária, CP 364

CEP 79804-970, Dourados (MS), Brasil

conradosathler@ufgd.edu.br

\section{FONTE DE FINANCIAMENTO}

O estudo foi desenvolvido com

financiamento próprio (dos autores)

\section{CONFLITO DE INTERESSE}

Os autores declararam não

haver conflitos de interesse.

\section{O estudo foi desenvolvido no}

Laboratório Clínica de Psicologia

Aplicada, Faculdade de

Ciências Humanas, Universidade

Federal da Grande Dourados,

Dourados (MS), Brasil.

\section{RESUMO}

Contextualização: Os cursos brasileiros de Psicologia iniciaram suas atividades em 1953 e somente após dez anos regulamentou-se a profissão com a fixação de um currículo mínimo na formação. Portanto, são mais de 50 anos de ensino e algumas marcas podem ser notadas. Alterações foram necessárias do início direcionado à formação clínica individual até a atuação nos equipamentos da Reforma Psiquiátrica. Objetiva-se discutir essas alterações por meio de relato e análise dos percursos dos autores. Descrição da experiência: Os autores são professores de Psicologia cujas formações ocorreram de 1983 a 2002 em instituições paulistas e paranaense. Investem em práticas docentes que atendem às demandas atuais da profissão. Neste relato são problematizadas suas próprias formações e experiências docentes e a pedagogia crítica foi o referencial desta análise. Os projetos de 10 cursos disponíveis pela internet, seus apontamentos estudantis e gestos de compartilhar as memórias da graduação compuseram o corpus. Resultados e Impactos: A concepção do processo histórico do ensino de Psicopatologia, ora individual, ora classificatória e a demanda dos equipamentos da rede de saúde mental disputam sentidos na formação dos psicólogos. Considerações finais: Em alinhamento às Diretrizes Curriculares Nacionais, a proposta do quadrilátero da formação é um princípio pedagógico fundamental para fortalecer o compromisso ético profissional frente às demandas do SUS.

PALAVRAS-Chave: Educação superior. Psicologia social. Psicopatologia. Saúde mental. Saúde pública.

\section{ABSTRACT}

Contextualization: The Brazilian Psychology courses began their activities in 1953 and after ten years the profession was regulated with the establishment of a minimum curriculum in the formation. Therefore, there are more than 50 years of teaching and some marks can be registered. Changes were necessary from the beginning directed to the individual clinical training to the performance in the equipment of the Psychiatric Reform. We aim to discuss these changes through the reporting and discussion of the authors' journeys. Description of the experiment: The authors are Psychology teachers whose graduated from 1983 to 2002 in São Paulo and Paraná universities. They invest in teaching practices that consider the current demands of the profession. In this report their own formations and teaching experiences are problematized and Critical Pedagogy were the referential of this analysis. The projects of 10 courses available through the internet, their student notes and gestures of sharing the memories of graduation set up the corpus. Results and Impacts: The conception of the historical process of the teaching of Psychopathology, sometimes individual, sometimes classificatory and the demand of the equipment of the mental health network compete meaning in the formation of psychologists. Final considerations: In line with the National Curricular Guidelines, the proposition of the formation quadrilateral is a fundamental pedagogical principle to fortify the professional ethical commitment to SUS demands. KEYWORDS: Higher education. Social psychology. Psychopathology. Mental health. Public health. 


\section{Contextualização}

Este relato de experiência visa apresentar, pelo viés da Pedagogia Crítica, um modelo de ensino de Psicopatologia que mesmo atendendo às demandas profissionais inscritas nas políticas de Saúde do Estado se localiza na contramão das tendências políticas de ensino atuais. Para isso, tocaremos brevemente na(s) história(s) do ensino de Psicopatologia de alguns cursos de Psicologia do interior dos estados de São Paulo e Paraná, onde se formaram os autores, objetivando apontar a presença opaca da Psicologia Social que invariavelmente está à margem das tendências teóricas majoritárias em Psicopatologia.

Naturalmente, os primeiros professores de Psicopatologia nos cursos de Psicologia não eram psicólogos. Via de regra, eram psiquiatras. Assim, nunca haviam atuado como psicólogos. Ainda hoje há, embora parcialmente, professores médicos e identificamos disciplinas que associam o sofrimento psicossocial à Psiquiatria. No entanto, encontramos vários cursos cuja formação do professor de Psicopatologia é em Psicologia, pós-graduados em clínica, trabalho e saúde coletiva, entre outros. Esses dados são de amostragem de 10 cursos de graduação cujos Projetos Político-Pedagógicos (PPP) e corpo docente estão disponíveis na rede mundial de computadores.

Se considerarmos o histórico, a Psicologia recebe seu reconhecimento oficial como profissão em 1962 e é regulamentada após dois anos com as principais incumbências de realizar avaliação psicológica e clínica ${ }^{1}$. Este período caracterizou-se pela industrialização do país, pelo tecnicismo escolar e pelo acesso restrito à saúde aos trabalhadores formais ${ }^{2,3}$. A Saúde Mental manteve-se, deste período até próximo à virada do século, centrada nos hospitais psiquiátricos, como podemos ver na publicação documental de Firmino ${ }^{4}$, reproduzida no best seller "Holocausto Brasileiro", de Arbex ${ }^{5}$.

Como vimos nessas obras e no registro de Amarante sobre a visita de Franco Basaglia ao Brasil ${ }^{6}$, o nome hospital não cabe às entidades asilares de transtorno mental, pois não produzem saúde, ao contrário, são campos de concentração promotores do extermínio de uma parte da sociedade.

Ensinava-se, então, a Psicopatologia como um saber essencial para a classificação de pessoas (seleção de pessoal, organização de salas de aula, pareceres criminológicos etc), para clínica individual e atuação em manicômios. O exercício do ensino se dava nesses cenários e as variações, como as experiências e abordagens voltadas à expressão e libertação corporal das cadeias opressoras do Estado, ganhavam espaço nos discursos acadêmicos de protesto. Assim, as abordagens como Gestalt Terapia, Psicodrama e Biodança, cujos discursos se voltavam à defesa da expressão livre e ao repúdio à repressão, por exemplo, ganharam expressividade neste período 7 .

Esse ensino, vivenciado no papel de estudante de um dos autores, foi fundamentado na apresentação de sinais e sintomas dos transtornos mentais e no relato de intervenções junto aos pacientes e familiares. A atividade que ilustrava as práticas era uma visita monitorada a um manicômio. O objetivo era preparar o estudante para encaminhamentos hospitalares e terapêuticos, orientações familiares, identificação de usuários de drogas e atividades ligadas ao funcionamento global dos hospitais psiquiátricos.

Havia também a crítica aos modelos vigentes: uma leitura inicial de Michel Foucault era realizada, os filmes que denunciavam as práticas hospitalares de tortura eram debatidos e a clínica terapêutica era valorizada como saída viável para familiares e pacientes.

No período de transição política houve algum recrudescimento das práticas clínicas e, pelo menos parcialmente, a apresentação das primeiras práticas exitosas do movimento da luta antimanicomial. Esses relatos eram apresentados como possibilidades futuras, contudo as avaliações recaiam quase exclusivamente sobre 
a prática manicomial. Para validar esses conteúdos havia alguma intervenção como a aplicação de uma anamnese ou de outras entrevistas diagnósticas com pacientes psiquiátricos. Registramos a aversão dos estudantes a essas experiências, mas o enfrentamento dessa repulsa era visto como um sinal de bom preparo para assumir um posto profissional confiável.

Com a democratização e o surgimento, na esteira da Constituição Federal de 1988, das Políticas Públicas de Saúde, de Assistência Social e também com a nova Lei das Drogas, o campo social do sofrimento mental tem passado por alterações. As instituições públicas se tornaram as maiores empregadoras dos psicólogos o que exigiu a busca deformação de profissionais capacitados para novos postos de trabalho ${ }^{8}$. O estudo da Saúde Pública entra no rol de conhecimentos apropriados ao novo momento.

O conceito de Saúde Coletiva foi cunhado por atores sociais ligados ao SUS e nele expressou o desejo da compreensão da saúde processual (em oposição à dualidade saúde-doença), da participação social, da ampliação da clínica e, por fim, da busca da Integralidade e da Universalidade como direito. Derivado da Reforma Sanitária, esse foi um movimento político e em suas estratégias havia a introdução de produção e divulgação de conhecimentos nas universidades devido à compreensão de que a academia deveria agregar-se ao plano geral de ações, pois supunham que se a universidade continuasse formando profissionais somente para o mercado de trabalho não haveria possibilidade de avanço nas práticas almejadas ${ }^{9}$.

Para fazer frente a essa inovação foram apresentadas pautas para a construção das Diretrizes Curriculares Nacionais (DCN) dos cursos da área da Saúde. As novidades consistiam na habilitação de egressos para a saúde da família, na formação de conselheiros do Controle Social e na capacitação de gestores ${ }^{10}$. As diretrizes foram sancionadas entre 2001 e 2004. Não foram os Conselhos Federais nem o Conselho de Educação os responsáveis pela sua elaboração, foram as associações profissionais, no caso da Psicologia esse debate foi proposto pela Associação Brasileira de Ensino de Psicologia (ABEP).

Essas pautas de formação profissional eram políticas e deviam enfrentar a identidade profissional ligada à clínica tradicional, práticas excludentes e avaliação classificatória ${ }^{8}$. A política na ABEP foi de convencimento dos coordenadores dos cursos de que a Psicologia precisava mudar o perfil do egresso.

Essa renovação forçou a adaptação da academia de ensino. Obviamente, esta narrativa planifica as imensas diferenças das instituições formadoras de diversos níveis. Entretanto, por mais hegemônicos que fossem os discursos biomédicos, por mais argumentos atuais que esses discursos disseminassem, com todas as armas de sedução e promessas de drogas da felicidade e fenecimento do mal-estar, havia, agora, a necessidade de criar uma resposta à educação crítica inserida logo no primeiro conjunto de metas formativas. Vamos esclarecer com o recorte abaixo, parte das DCN para graduação em Psicologia:

Art. $3^{\circ} \mathrm{O}$ curso de graduação em Psicologia tem como meta central a formação do Psicólogo voltado para a atuação profissional, para a pesquisa e para o ensino de Psicologia, e deve assegurar uma formação baseada nos seguintes princípios e compromissos: [...]

b) Compreensão dos múltiplos referenciais que buscam apreender a amplitude do fenômeno psicológico em suas interfaces com os fenômenos biológicos e sociais;

c) Reconhecimento da diversidade de perspectivas necessárias para compreensão do ser humano e incentivo à interlocução com campos de conhecimento que permitam a apreensão da complexidade e multideterminação do fenômeno psicológico;

d) Compreensão crítica dos fenômenos sociais, econômicos, culturais e políticos do País, fundamentais ao exercício da cidadania e da profissão;

e) Atuação em diferentes contextos considerando as necessidades sociais, os direitos humanos, tendo em vista a promoção da qualidade de vida dos indivíduos, grupos, organizações e comunidades $[\ldots]^{11}$. 
Essa escrita é marcada pela nova concepção do papel do psicólogo na sociedade. Ao afirmar "Compreensão dos múltiplos referenciais que buscam apreender a amplitude do fenômeno psicológico $[\ldots]^{11 "}$ a lógica formativa se inverte, pois os múltiplos referenciais não são para explicar algo, mas para tocá-lo. E reitera [...].

Reconhecimento da diversidade de perspectivas necessárias para compreensão do ser humano e incentivo à interlocução com campos de conhecimento que permitam a apreensão da complexidade e multideterminação do fenômeno psicológico [.... $]^{11}$.

que traz, pela via da interlocução com os campos de trabalho, a interdisciplinaridade na descentralização do saber psicológico e o qualifica para o diálogo em saúde. Por fim, os valores expostos em "[...] considerando as necessidades sociais, os direitos humanos, tendo em vista a promoção da qualidade de vida $[. . .]^{11^{1 \prime}}$ marcam o deslocamento do objeto de trabalho da face psíquica para a psicossocial.

Evidenciando a temática da Saúde, adicionamos o recorte abaixo:

Art. $4^{\circ} \mathrm{A}$ formação em Psicologia tem por objetivos gerais dotar o profissional dos conhecimentos requeridos para o exercício das seguintes competências e habilidades gerais:

a) Atenção à saúde: os profissionais devem estar aptos a desenvolver ações de prevenção, promoção, proteção e reabilitação da saúde psicológica e psicossocial, tanto em nível individual quanto coletivo [...];

f) Educação permanente: os profissionais devem ser capazes de aprender continuamente, tanto na sua formação, quanto na sua prática, e de ter responsabilidade e compromisso com a sua educação e o treinamento das futuras gerações de profissionais, estimulando e desenvolvendo a mobilidade acadêmica ${ }^{11}$.

Assim, torna-se efetiva a busca de mudança da assistência curativa para a preventiva com o compromisso ético-político na formação profissional.

Considerando, então, concretizadas as necessidades de formação geral, voltemos nossa atenção à Psicopatologia. Qual deveria ser a colaboração deste conhecimento à formação do psicólogo nesse novo contexto? Buscamos responder a esta questão em algumas medidas político pedagógicas em experimento e depois elencamos as barreiras encontradas neste processo.

Primeiramente, pensamos que há especificidades da Psicopatologia que não podem ser negligenciadas: a história da loucura, a lógica da doença mental como uma construção histórica produtora de transtornos que correspondem a condições de existência específicas, a Psicopatologia Geral - estudo das alterações das funções psicológicas -, e as Classificações dos desvios de desenvolvimento, de personalidade e das normas sócio-identitárias. Esses conteúdos devem ser contextualizados e problematizados analítica e criticamente.

A transformação do campo de atuação passou da clínica privada para a atividade pública e coletiva. O Centro de Atenção Psicossocial (CAPS) e outros equipamentos da lógica substitutiva alteraram significativamente as práticas. Ao serem abertos, os CAPS possuíam a tarefa da reabilitação da população antes internada. Havia duas frentes para a reinserção social: assistência aos usuários e instalação de Residências Terapêuticas com o devido acolhimento. Nos tempos atuais, passados vinte anos, já não há mais uma população expressiva internada, há, sim, uma população que enfrenta transtornos e necessita de ajuda para não se cronificar. Em outra frente, o matriciamento - atuação junto às equipes de Estratégia da Saúde da Família (ESF) - e a prevenção se fazem prementes.

O egresso das Instituições de Ensino Superior (IES) de hoje deve saber atuar nas políticas públicas e dar respostas coletivas e políticas, não mais da clínica tradicional. Um novo foco, então, se anuncia: a demanda pedagógica de desenvolvimento de análises institucionais e sociopolíticas. 


\section{Descrição da experiência}

Os autores, inseridos na formação para esse novo campo, identificados à Saúde Coletiva e Saúde Mental, lançam mão de experimentar gradativamente a integração ensino-serviço-comunidade, na rede SUS. Um recurso compartilhado por todos é a inserção do alunado nas ações do Controle Social. Assim, a participação nas conferências e conselhos municipais de diversos segmentos propicia a compreensão da lógica dos trabalhadores, usuários e gestores e insere ainda o debate democrático e a formação cidadã.

Outra aposta foi buscar o deslocamento da gestão para a Atenção Básica como estratégia de formação de estagiários, associando-os ao Programa de Melhoria de Qualidade e Acesso (PMAQ). Esse recurso tem permitido problematizar o pensamento hospitalocêntrico para uma alternativa de Clínica Ampliada ${ }^{11}$ onde os recursos comunitários e técnicos compartilhados potencializam as ações.

Por fim, há também a experiência do trabalho ambulatorial com o recurso alternativo da articulação da clínica e o empoderamento dos usuários, estimulando a formação de associações desses e de familiares e, também, investindo no matriciamento dos serviços. Além disso, as oficinas com atividades coletivas de convivência, expressão e geração de renda são apontadas como estratégias no desenvolvimento da clínica ampliada.

Essas alterações em estágios e programas de curso alteram os temas discutidos em classe. Como exemplo: os problemas conceituais passam pela literatura, "O Alienista" de M. Assis (1882) torna-se objeto de análise. Clássicos da Psicanálise como "O Futuro de uma ilusão" e "O Mal-estar na civilização" de S. Freud (1927; 1930) são debatidos. Os problemas do cotidiano profissional como a política de proteção integral às crianças, os impasses sobre as políticas sobre drogas, a violência nas escolas e a medicalização da população são temas eleitos para o desenvolvimento de uma posição sobre o sofrimento psicossocial, antes apenas neuroses e psicoses eram temas discutidos.

As avaliações deixam de ser puramente conceituais e passam a ser dialógicas e centradas em projetos de intervenção ${ }^{12}$. Dessa forma, as sugestões dos alunos são incluídas nos programas de ensino das futuras turmas. Além disso, os autores participam de um grupo de estudos no qual essas experiências pedagógicas são discutidas e avaliadas desde 2012.

\section{Resultados e impactos}

As alternativas apresentadas impactam a formação de psicólogos como profissionais do SUS. Propiciam os deslocamentos da clínica centrada nos modelos medicalizantes e hospitalocêntricos para a Clínica Ampliada, na qual o acesso e a qualidade dos serviços, o valor do trabalhador e dos recursos comunitários são centrais e valorizam a rede de atenção ${ }^{13}$.

As práticas docentes experimentadas são identificadas com as propostas do modelo pedagógico do Quadrilátero da Formação que compreende ensino, gestão, atenção e controle social em seu currículo ${ }^{14}$.

No entanto, como observamos nos PPP investigados, há variações de conteúdo que imprimem diferenças significativas ao ensino de Psicopatologia. A regularidade é que a disciplina se encontra no rol daquelas ofertadas na primeira metade dos cursos. Provavelmente isto ocorre por ser ela considerada um fundamento para o ensino das disciplinas relativas aos campos de trabalho, como Psicologia da Saúde, Escolar, Clínica etc..

Desta forma, compreendemos os componentes curriculares como produtores de uma organicidade nos PPP e funções específicas são desenvolvidas por cada um deles. Logo, nossa observação não impinge censura aos PPP ou interferência na opção 
política fundante de cada IES. Essas construções pedagógicas são, certamente, calcadas em uma filosofia e consequente concepção de missão própria de cada instituição e do compromisso ético de manter-se articulado aos movimentos e transformações sociais nas quais se inserem seus egressos.

A Psicopatologia, como disciplina que serve de base para as futuras discussões de clínica, educação, trabalho e saúde mental [...], deve buscar ampliar seu escopo de abrangência, correndo o risco de ao optar pelo ensino apenas da Psicopatologia Clínica não ser suporte suficiente para o desenvolvimento das ações da Clínica Ampliada ou, ao apresentar exclusivamente a vertente biológica ligada à Psicopatologia Geral, não apoiar os campos sociais de atuação de seus egressos.

Avançando um pouco mais no pensamento sobre o currículo, apontamos que a apresentação da Psicopatologia como uma atividade classificatória em uma epistemologia restrita ao pensamento positivista torna-se um argumento de resistência voltado ao desenvolvimento do campo de trabalho mais expressivo de hoje: a Saúde Mental. Forma-se uma resistência à compreensão do sujeito e à formação subjetiva de seu transtorno, levando o profissional a excluir-se das tendências políticas de abordagem da Saúde Mental, como a desinstitucionalização e as intervenções comunitárias $^{14,15}$.

\section{Considerações finais}

Os embates discursivos desafiam a Psicopatologia e seu ensino a enfrentar as fronteiras sociais do conhecimento tradicional e as tendências sociais, políticas e econômicas comandadas pela Psicopatologia dos Códigos (DSM e CID) e pelos discursos farmacológicos e biomédicos.

A formação de conhecimentos: comunitários, de direitos individuais e coletivos, da atuação política nos campos do trabalho, da problematização dos mecanismos sutis de exclusão social e para participação nos Órgãos de Controle Social precisam ser incrementados na formação profissional.

Por fim, a proposta do Quadrilátero da Formação é, para nós, um princípio pedagógico de valor para a formação e transformação social pela via da Saúde como direito de cidadania.

\section{Referências}

1. Brasil. Decreto n. 53.464 de 21-01-1964 Regulamenta a Lei n. 4.119, de agosto de 1962, que dispõe sobre a Profissão de Psicólogo. Diário Oficial da União [Internet]. Brasília, DF, 24 jan. 1964 [citado em 2017 Jul. 11]. Disponível em: http:// site.cfp.org.br/wp-content/uploads/2008/08/decreto_1964_53464.pdf

2. Cunha MV. A educação no período Kubitschek: os centros de pesquisas do INEP. Rev Bras Estud Pedagogicos. 1991;72(171):17595. http://dx.doi.org/10.24109/2176-6681.rbep.72i171.1294.

3. Cunha LEF, Alves, TKC. Os acordos Mec-Usaid e seu impacto no sistema de ensino superior brasileiro. In: Anais da XII HISTEDBR e X Seminário de Dezembro [Internet]; 2007 Dez 2-4; Caxias, BR. Caxias (MA): UNICAMP; 2014 [citado em 2017 Jul 5]. p. 1-13. Disponível em: http://www.histedbr.fe.unicamp.br/acer_histedbr/jornada/jornada12/artigos/2/ artigo_eixo2_81_1410814891.pdf

4. Firmino H. Nos porões da loucura. $2^{\mathrm{a}}$ ed. Rio de Janeiro (RJ): Codecri; 1982.

5. Arbex D. Holocausto brasileiro: vida, genocídio e 60 mil mortes no maior hospício do Brasil. São Paulo (SP): Geração Editorial; 2013.

6. Amarante P. Saúde mental e atenção psicossocial. Rio de Janeiro (RJ): Fiocruz; 2007.

7. Hirye HMCM. (Orgs.). Práticas alternativas: campo da psicologia? São Paulo (SP): Express; 1998.

8. Huning S, Silva AK, Silva WVN, Lessa FMS. Formação para o SUS nos cursos de psicologia em Alagoas. Psicol Estud. [Internet]. 2013 Mar [citado em 2015 Out 11];18(1):157-67. Disponível em: http://www.scielo.br/scielo. php?script=sci_arttext\&pid=S1413-73722013000100016\&lng=pt\&nrm=iso

9. Ceccim RB, Ferla AA. Educação e saúde: ensino e cidadania como travessia de fronteiras. Trab Educ Saúde. 2008;6(6):44356. http://dx.doi.org/10.1590/S1981-77462008000300003.

10. Brasil. Ministério da Saúde. Secretaria de Gestão do Trabalho e Educação em Saúde. Departamento de Gestão na Saúde. Políticas de Formação e Desenvolvimento para o SUS: caminhos para a educação permanente em saúde [Internet]. Brasília 


\section{ighe}

(BR): Ministério da Saúde (BR); 2003 [citado em 2015 Out 11]. Disponível em: http://bvsms.saude.gov.br/bvs/publicacoes/ pol_formacao_desenv.pdf

11. Brasil. Conselho Nacional de Educação. Câmara de Educação Superior. Resolução no 8, de 7 de maio de 2004. Institui as Diretrizes Curriculares Nacionais para os Cursos de Graduação em Psicologia. Diário Oficial da União. Brasília, DF, 18 maio 2004 [citado em 2017 Jul 13]; Seção 1. p. 16. Disponível em: http://portal.mec.gov.br/cne/arquivos/pdf/rces08_04.pdf

12. Paula HF, Moreira AF. Atividade, ação mediada e avaliação escolar. Educ Rev. 2014;30(1):17-36. http://dx.doi.org/10.1590/ S0102-46982014000100002.

13. Campos GWS. Saúde Paideia. São Paulo (SP): Hucitec: 2003.

14. Ceccim RB, Feuerwerker LCM. O quadrilátero da formação para a área da saúde: ensino, gestão, atenção e controle social. PHYSIS: Rev Saúde Coletiva [Internet]. 2004 [citado em 2017 Jul 10];14(1):41-65. Disponível em: http://www.scielo.br/ pdf/physis/v14n1/v14n1a04.pdf

15. Fonte EMM. Da institucionalização da loucura à reforma psiquiátrica: as sete vidas da agenda pública em saúde mental no Brasil. Estudos de Sociologia [Internet]. 2012 [citado em 2017 Jul 13];1(18). Disponível em: http://www.revista.ufpe.br/ revsocio/index.php/revista/article/view/60/48

\section{Contribuição dos autores}

Todos os autores participaram do planejamento e execução do trabalho. 